\title{
AUTORIA, AUTORIDADE E AUTONOMIA NO TRABALHO ACADÊMICO- PROFISSIONAL: UMA REFLEXÃO BIOGRÁFICA
}

Sabrina Guedes ${ }^{\mathrm{i}}$

Mônica Macedo ii

\begin{abstract}
Resumo: Este artigo tem o objetivo de revisitar a biografia acadêmico-profissional das autoras, através da seguinte tríade teórica: autoria, autoridade e autonomia. Traremos para o debate alguns dos seguintes teóricos: Bakhtin, Foucault, Paulo Freire, que nos ajudarão a discutir o processo individual e coletivo sobre o empoderamento docente. Colocaremos em evidência a trajetória acadêmico-profissional de cada uma das autoras, as transformações, as mudanças no percurso, desafios e conquistas entre pares e no coletivo das instituições educacionais. Analisaremos ainda o encontro profissional, a parceria da dupla, as produções realizadas e os projetos construídos, realçando os pontos significativos que se fazem presentes nessa constituição seja de forma individual, bem como em outros momentos e situações entre pares.
\end{abstract}

Palavras-chave: Autoria; Autoridade; Autonomia.

\section{AUTORÍA, AUTORIDAD Y AUTONOMÍA EN EL TRABAJO ACADÉMICO- PROFESIONAL: UNA REFLEXIÓN BIOGRÁFICA}

Resumen: Este artículo tiene como objetivo revisar la biografía académico-profesional de los autores, a través de la siguiente tríada teórica: autoría, autoridad y autonomía. Traeremos al debate a algunos de los siguientes teóricos: Bakhtin, Foucault, Paulo Freire quienes nos ayudarán a discutir el proceso individual y colectivo sobre el empoderamiento docente. Destacaremos la trayectoria académico-profesional de cada uno de los autores, las transformaciones, cambios en el rumbo, desafíos y logros entre pares y en el colectivo de instituciones educativas. También analizaremos el encuentro profesional, la asociación del dúo, las producciones realizadas y los proyectos construidos, destacando los puntos significativos que están presentes en esta constitución tanto a nivel individual como en otros momentos y situaciones entre pares.

Palabras clave: Autoría; Autoridad; Autonomía.

\section{Introdução}

Trazer para o palco da discussão acadêmico-profissional uma análise que faz parte do nosso cotidiano como educadoras e fundamentalmente, como foi se constituindo ao longo da nossa trajetória em comum como pesquisadoras, é afirmar as potencialidades individuais e coletivas de ambas as autoras, que foram se constituindo a partir das experiências vividas conjuntamente e em espaços e momentos diferenciados. 
Refletir, e mesmo afirmar que a gênesis do nosso trabalho carrega em si a constituição desses três elementos: autoria, autoridade e autonomia, é endossar a propriedade que conquistamos sobre o fazer pedagógico que nos identifica e conduz nossas ações além do espaço "próprio", a escola. Um movimento de lutas, de um combate por vezes silencioso, mas na maior parte dos momentos, um ecoado de vozes que se transformam em atividades laborais, a partir das reflexões e registros de toda ordem que foram compondo nossos ofícios de professoras.

Nossos processos de profissionalização passaram por momentos significativos que enriqueceram a trajetória de cada uma de nós, empoderando e corporificando a produção teórico-científica que nos identifica. Esses momentos foram marcados por estudos, análises de trabalhos em torno das formações docentes que realizamos e um repensar de forma diversificada as ações que fomos realizando ouvindo, escrevendo, lendo e discutindo.

Ser autora de um produto intelectual é afirmar que a autoridade pedagógica faz parte de uma coerência que temos entre a teoria e prática, de forma consciente e crítica, ainda que enfrentando percalços próprios de nossos contextos de atuação, pois como professoras e pesquisadoras também temos noção das dificuldades desse campo pedagógico, social, político e cultural.

Com isso, dizemos para os nossos pares, instituições e onde estivermos, que somos pesquisadoras e essa afirmação é diária e independe dos espaços e pessoas que nos gerenciam. Isso precisa ser demarcado e reafirmado cotidianamente.

\section{Processos Emancipatórios: autoria, autoridade e autonomia}

Falar de autoria, autoridade e autonomia no trabalho docente é falar de si mesmo e de sua trajetória. São conceitos que requerem a todo o tempo a aliança com a reflexão, um movimento de fazer-estudar-avaliar constante no trabalho que vai se desenhando, se encorpando. Autoria, "autonomia e autoridade não são só atributos individuais, mas se inscrevem numa malha de influências que atingem o coletivo da profissão, construindo uma cultura". (http://coralx.ufsm.br/revce/revce/2004/02/a5.htm)

Um processo emancipatório docente, onde o professor é o agente ativo da sua atividade pedagógica, valorizando a intencionalidade de suas ações e ideias, avaliando as ações externas, 
a fim de que possam contribuir na condução do seu trabalho, é um caminho que precisa ser conquistado, exercitado diariamente.

A autoridade é entendida em sintonia com sua raiz etimológica, ou seja, associada à ideia de autor, de criador, de compositor, de inventor ou arquiteto, ou ainda, alguém que se legitima por sua obra. Sendo assim, a autoridade do professor é decorrente de sua produção científica e do exercício de seus processos, o qual autoriza-se pelas suas obras, suas criações e sua palavra explícita. Um agente que se encontra na origem de sua própria ação e que é capaz de se autorizar. (http://coralx.ufsm.br/revce/revce/2004/02/a5.htm)

Nesse sentido, a fundamentação é muito importante, pois além da troca e das reflexões com os nossos pares, nos apresenta possibilidades de aprofundamento sobre o nosso próprio fazer, e sobre esses processos que estamos aqui apresentando.

O professor com esse perfil assina aquilo que é próprio da sua profissão, do que lhe cabe dentro do universo educacional. Contudo, esse perfil não nasce conosco. Através de nossas vivências pedagógicas e acadêmicas vamos dando corpo às linhas de pensamento, às escolhas metodológicas e aos sentidos ao nosso fazer.

Fala-se hoje, com insistência, no professor pesquisador. No meu entender o que há de pesquisador no professor não é uma qualidade ou uma forma de ser ou de atuar que se acrescente à de ensinar. Faz parte da natureza da prática docente a indagação, a busca, a pesquisa. $\mathrm{O}$ de que se precisa é que, em sua formação permanente, o professor se perceba e se assuma, porque professor, como pesquisador. (FREIRE, 1996, p. 29)

É um movimento de conscientização que não acontece somente no desejo de fazer diferente e querer mudar, sair do status quo, mas de se impor enquanto teórico e responsável pelos movimentos circundantes do chão da sala de aula. E essa conscientização se torna um processo permanente que vai condensando nossas escolhas, fazeres e sentidos e que vamos atribuindo às experiências cotidianas que aí vão se desvelando. O cotidiano em conjunto com a fundamentação e a reflexão sobre a práxis é uma grande chave para potencializar nossa constituição profissional.

Ao analisar as questões de autonomia e de autoridade docente encontra-se a crítica ao processo de proletarização dos professores em suas diferentes dimensões. Tais críticas estão relacionadas ao conhecimento docente e a sua formação, seja ela inicial ou continuada e as formas de controle externo, mais especificamente aos processos de avaliação, aos dispositivos pedagógicos, como os livros didáticos, metodologias exógenas geralmente prontas. (http://coralx.ufsm.br/revce/revce/2004/02/a5.htm) 
A formação docente é um espaço/campo onde é permitido esse trânsito de discussão, esclarecimento que leva à transformação significativa na prática docente. É a práxis-pedagógica acontecendo o tempo inteiro, (re) fazendo com que o professor altere a sua ação, sendo diferente e permitindo um constante melhoramento no ato pedagógico, a partir do que se estuda, do que se avança e do que se pretende ampliar e aprofundar na nossa prática.

É preciso que fique claro que, por isto mesmo que estamos defendendo a práxis, a teoria do fazer, não estamos propondo nenhuma dicotomia de que resultasse que este fazer se dividisse em uma etapa de reflexão e outra, distante, de ação. Ação e reflexão se dão simultaneamente (FREIRE, 1987, p. 125)

Um acontecer pedagógico que se incorpora na persona de cada um individualmente e no todo da categoria, especialmente naqueles que se comprometem com a transformação e na mudança estrutural de fato.

\section{Empoderamento docente: uma teoria ou uma realidade?}

Há uma fala muito contundente na Academia e nas formações docentes com relação ao empoderamento docente. Seria uma realidade ou uma utopia?

A utopia exige o conhecimento crítico. É um ato de conhecimento. Eu não posso denunciar a estrutura desumanizante se não penetro para conhecê-la. Não posso anunciar se não conheço, mas entre o momento do anúncio e a realização do mesmo existe algo que deve ser destacado: é que o anúncio não é anúncio de um anteprojeto, porque é na práxis histórica que o anteprojeto se torna projeto. É atuando que posso transformar meu anteprojeto em projeto. (FREIRE, 1980, p. 28).

É uma conquista que vem sendo trabalhada a partir do momento que a ação docente toma corpo e adquire a identidade de um determinado educador, diferente do outro. Ao mesmo tempo em que vem sendo construída, pois quando a reflexão e a experiência pedagógica transitam e se interseccionam, o produto gerador é a teoria advinda dessa experiência. É o respeito pelo que se faz. E para isso "os processos de subjetivação e de objetivação que fazem com que o sujeito possa se tornar, na qualidade de sujeito, objeto de conhecimento." (FOUCAULT, 2004, p. 236).

Ao adentrarmos, no início, nos espaços formativos, principalmente o escolar, na maioria das vezes, ainda estamos tímidos. Trazemos em nossa bagagem representações, valores e Revista Interinstitucional Artes de Educar. Rio de Janeiro, V. 7, N. 1 - pág. 686-700 janeiroabril de 2021: "Pedagogias Vitais: Corpo, Desejo e Educação" DOI: 10.12957/riae.2021.53461 
conceitos acerca do magistério, do que é ser professor. Vivemos esse momento como um período de descoberta da profissão como ingressantes. Trazemos também sonhos e expectativas que, em muitas vezes, não se realizam exatamente como pensamos, ou ainda, alguns modelos que tínhamos vão ficando pela trajetória. Todo esse percurso vai nos subjetivando, nos marcando sempre de maneira aberta, onde os sentidos de ser professor se pretendem dados à priori, mas que nunca o são. Eles vão se constituindo de acordo com tempos, espaços, valores e um arcabouço de uma miríade de momentos que fazem com que reflitamos e nos rearticulemos nas nossas ações.

E como bem sabemos, nem sempre esse espaço escolar, inicialmente, colabora para o processo de empoderamento docente. A realidade muitas vezes é tão bruta que nos permite poucos momentos de reflexão sobre a prática que realizamos, pois enfrentamos as questões de como o tempo se organiza em cada espaço, suas condições de forma geral e, então, nos deparamos com dificuldades e obstáculos que nunca são os mesmos em todos os espaços e momentos. Isso pode gerar um pouco de isolamento, fragilizar uma atitude de análise mais coletiva ou pode ser a condição de superação constante.

Mas o empoderar-se na profissão e como profissional não precisa ser uma realidade distante, utópica ou apenas teórica. Pode e deve se materializar, especialmente, na conscientização da importância que o trabalho docente tem, no nível de compromisso que empregamos, embora não possamos controlar esses processos, pois todos eles são mediados pela linguagem, pois

A palavra do outro deve transformar-se em minha-alheia (ou alheia-minha). A distância (vnienakhodímost) e o respeito. No processo da comunicação dialógica com o objeto, este se transforma em sujeito (o outro eu). (BAKTHIN, 2003, p. 381)

Uma realidade que vai tomando forma e se distinguido no contato com o outro, seus pares, gestores, nos momentos de formação continuada, enfim, na vivência da prática docente e nas trocas qualitativas, em vários espaços e momentos. A linguagem (em todos os seus campos e não só o verbal) aqui assume uma função importantíssima na constituição de sentidos, valores e conceitos que vão sendo reconfigurados e deslocados ininterruptamente, pois nos constituímos através do outro.

Um processo que se constrói, se (re)fazendo, desafiando o professor à não aceitação do aparentemente natural, mas ao contrário, lutando pelo seu papel profissional na coletividade de 
suas ações, ainda que elas não sejam materializadas. Os sentidos em disputas em suas interações que vão se dando, vão marcando os sentidos da nossa profissionalidade.

Autoria, autoridade e autonomia, são conceitos que dialogam e advêm de naturezas diferenciadas, não seguindo uma relação linear entre si. Cada experiência, individual e/ou coletivizada, marcará o tom, o momento e o sentido da vivência docente, por isso é que, na formação permanente dos professores, o momento fundamental é o da reflexão crítica sobre a prática (FREIRE, 1996, p. 29).

A autoria está ligada à produção de sentidos que cada um materializa no seu fazer, onde o registro escrito é parte importante para sedimentar conhecimentos, pontos de vista e paradigmas de seu próprio trabalho.

Os estudos teóricos de Bakhtin trazem algumas contribuições para a nossa discussão sobre autoria.

A consciência autoral sobre a produção textual em Bakhtin traz elementos importantes para (re)pensarmos o papel que o professor tem sobre seu trabalho e todo seu fazer pedagógico, constituindo-o como um agente de ação através do discurso que vai sendo constituído. Segundo a concepção de Foucault:

A noção de Discurso é empregada como: Um conjunto de regras anônimas, históricas sempre determinadas no tempo espaço, que definiram em uma dada época, e para uma área social, econômica, geográfica, ou linguística dada, as condições de exercício da função enunciativa. (FOUCAULT, 1960, p. 43)

O que é próprio do arcabouço teórico do professor, seu patrimônio intelectual, é algo imaterial que lhe pertence, mas que é traduzido no trabalho pedagógico que produz e o representa. A criação de algo novo que carrega a sua assinatura.

Nos dias atuais, a o conceito de autoria está ligado diretamente ao indivíduo que tem a sua produção intelectual realizada. E para tal, esse é um processo constituído através das práticas sociais, das experiências vividas. No âmbito da escola, isso é fundamental para o encaminhamento de uma prática emancipadora, como nos diz Freire:

Uma das tarefas mais importantes da prática educativa-crítica é propiciar as condições em que os educandos em suas relações uns com os outros e todos com o professor ou a professora ensaiam a experiência profunda de assumirse. Assumir-se como ser social e histórico, como ser pensante, comunicante, transformador, criador, realizador de sonhos, capaz de ter raiva porque capaz de amar. (Freire, 2000, p. 46) 
As transformações, as mudanças são inerentes ao ser humano e traduzem esse inacabamento, mesmo que pense que ao dar origem a alguma coisa, isto está pronto, ao contrário, os desdobramentos diários trarão novas experiências e teorias.

A autoridade se constrói pela fundamentação teórica e pelo conhecimento constituído na ação docente, o que resulta na intencionalidade dessa ação.

A autonomia envolve não só o fazer, mas também o pensar esse fazer. Essa elaboração vai aos poucos constituindo uma autonomia intelectual, na qual o sentido de seu fazer é constituído. "O respeito autonomia e à dignidade de cada um é um imperativo ético e não um favor que podemos ou não conceder uns aos outros" (FREIRE, 1996, p. 59). Não temos a competência pessoal de dizer, determinar quem terá ou não autonomia. É uma conquista pessoal que traz compreensões que cada um traz de si e de seu trabalho, além de incorporar os resultados teóricos, ideológicos, filosóficos... de muitas correntes que o traduzem e o diferenciam deste ou daquele profissional.

Executar, não mecanicamente, mas sabendo exatamente o porquê, para quê, para quem e para onde, é delimitar com precisão o terreno histórico-social que se trabalha, com a responsabilidade necessária para que o trabalho transcorra com toda a competência profissional exigida.

É no exercício de fazer e de se refazer o sentido do trabalho docente, que o professor vai encorpando e vivenciando-os em graus que vão se consubstanciando através de sua prática, de forma consciente e compromissado politicamente com o coletivo.

\section{Percurso e trajetória: Uma faca de 2 gumes?}

Quando iniciamos a nossa profissão, como qualquer outra professora, carregamos representações, conceitos e valores que trazemos conosco, baseados em nossa formação cultural.

Essa bagagem vai ao mesmo tempo nos conduzindo e também, na maioria das vezes, entrando em choque com a realidade que enfrentamos no dia-a-dia da profissão docente. Partes dessa bagagem poderão se confirmar e outras terão que passar por uma transformação para que possamos continuar no caminho. Essa medida, só conquistamos com o exercício da reflexão sobre o que fazemos e pensamos. É o que chamamos de práxis. 
Mas, se os homens são seres do quefazer é exatamente porque seu fazer é ação e reflexão. É práxis. É transformação do mundo. E, na razão mesma em que o quefazer é práxis, todo fazer do quefazer tem de ter uma teoria que necessariamente o ilumine. O quefazer é teoria e prática. É reflexão e ação. Não pode reduzir-se. (FREIRE, 1987, p. 121)

A trajetória vai se transformando num processo de profissionalização quando estamos inteiros nessa relação com a profissão. Ao mesmo tempo nesse processo, é preciso refletir sobre nossos saberes e fazeres, nosso compromisso com o coletivo e a formação dos alunos, alimentar nossos desejos e gostos por ser professor.

É claro que percurso e trajetória são individuais e se anelam às nossas histórias de vida, nosso posicionamento frente ao mundo e nossa leitura de onde estamos, por que estamos, para que e para quem estamos de fato realizando a profissão.

Essas reflexões passam por uma vocação, por uma significação muito íntima e poderosa pela escolha que fizemos. Para isso, as trajetórias podem não ser tão retilíneas. Podem sofrer cortes, rupturas num movimento dialético todo o tempo.

Para isso, é preciso que realmente, saibamos, sintamos até que ponto nos identificamos com aquilo que escolhemos como profissão, ainda que passemos agruras, contradições e condições muitas das vezes inimagináveis diante do que, no início, trazíamos em nossa bagagem.

Quando olhamos pra trás e percebemos o que enfrentamos e o quanto caminhamos é importante para qualificar a nossa trajetória docente. E então, olharmos pra frente e continuarmos a refletir. Isso é importante para que a nossa história docente, não seja apenas um percurso e sim uma trajetória.

Fazer parte da instituição pública, para muitos, é um sonho que se concretiza no fazer diário, no conhecimento dos espaços e possibilidades que o seu trabalho alcançará. Para outros, uma utopia, distante e que a cada dia da atualidade que vivemos se torna elástica e quase inatingível.

Estar num espaço para todos, público, é caminhar, transitar pelas alegrias e dificuldades, é resgatar o nosso compromisso profissional de fazermos a diferença significativa na vida das pessoas que nos circundam e "dependem e precisam" da nossa atuação laboriosa.

Lembranças de outrora, do início dessa jornada, desse caminhar profissional, eram quase românticas e ingênuas, trazendo antes de tudo o amor construído pela escola pública dos tempos escolares, dos bancos de estudos. Uma visão quase endeusada do que, porventura, na realidade viria e enfrentaríamos na luta que trouxemos no coração e nas marcas que a vida no 
colocou e feriu. Mas na certeza de que não tirou o brilho dos nossos olhos e vontade de sermos melhores profissionais a cada dia, pois a cada dia o percurso recomeça de onde parou e a trajetória continua na escrita de nossas experiências. Uma trajetória que se (retro)alimenta no estudo, no debruçar-se sobre o ofício, sobre o magistério e nos verdadeiros parceiros de trabalho que são os alunos.

\section{A relação com o institucional: possibilidades e desafios}

Ao ingressarmos no espaço institucional da escola não imaginamos o quanto ele seria significativo em nossa profissionalização, fosse por nos marcar por uma ausência de significado ou fosse por nos atar a vínculos. Mas sempre esse espaço é um espaço de formação, ainda que no início da carreira, poderíamos não ter isso claro.

Quando iniciamos nossa profissão, muitas vezes levamos sonhos, desejos e representações do que é ser professor. Ainda não o somos, mas com a cotidianidade de nossas ações vamos nos tornando professor e, como diz Freire:

Como professor crítico, sou um "aventureiro" responsável, predisposto à mudança, à aceitação do diferente. Nada do que experimentei em minha atividade docente deve necessariamente repetir-se. Repito, porém, como inevitável, a franquia de mim mesmo, radical, diante dos outros e do. Minha franquia ante os outros e o mundo mesmo e a maneira radical como me experimento enquanto ser cultural, histórico, inacabado e consciente do inacabamento. (1996, p. 50)

Nos deparamos com uma variedade de pares que nos apontarão possibilidades ou nos aprisionarão em suas teias, relações. Há professores que crescem juntos nesse espaço, dividindo angústias, trocando ideias, pensando e fazendo juntos. Há outros que se isolam ou são isolados, são competitivos no mau sentido, desagregam o grupo.

A aflição das primeiras experiências costuma gerar inseguranças, incertezas, mas também descobertas e informações. Daí se formam nossos primeiros paradigmas, que, na maioria das vezes, vamos perceber seus teores, mais à frente depois de algumas investidas.

Os pares com mais tempo, às vezes perderam o brilho nos olhos e se engessaram, impedindo que os novos possam fazer diferente. Às vezes os maduros também nos mostram o quanto podemos fazer mais e melhor, dividindo conosco, generosamente, o que constituíram em seus processos identitários docentes. 
Não há como precisar essa experiência no significado da profissionalidade, pois a diversidade é a marca e a dialeticidade, o movimento que nos faz pensar e repensar.

A conscientização e, neste sentido, um teste de realidade. Quanto mais conscientização, mais se "des-vela" a realidade, mais se penetra na essência fenomênica do objeto, frente ao qual encontramos para analisa-lo. Por esta mesma razão, a conscientização não consiste em "estar frente à realidade" assumindo uma posição falsamente intelectual. A conscientização não pode existir fora da "práxis", ou melhor, sem o ato ação-reflexão. Esta unidade dialética constitui, de maneira permanente, o modo de ser ou de transformar o mundo que caracteriza os homens. (FREIRE, 1980, p. 26)

A escola é um dos espaços de formação docente, talvez dos mais vigorosos, pois é ali, que empenhamos nossos esforços e entramos em contato com a mais pura realidade a que estamos expostos.

Precisamos, contudo, elevar esse espaço de maneira positiva, para que juntos, ali, possamos repensar nosso fazer e incorporarmos a finalidade das políticas públicas, qual seja fazer um trabalho que atenda e desenvolva a educação para todos.

Sabemos que a escola, enquanto instituição, ainda precisa caminhar na perspectiva inclusiva. Contudo, o espaço da escola pública tem logrado muitos êxitos. E são esses êxitos através dos inúmeros professores e trabalhos que geraram práticas reflexivas de qualidade, trocas entre os pares e uma produção teórica que extrapola os muros escolares.

O tempo que passamos na instituição "trabalho" nos traz elementos de uma formação que passa pelos longos anos de constituição profissional que confirma, baliza a ação pedagógica. E, essa ação é mediada pelo espaço formador da escola, pois sempre nos atravessa modificando essa prática, avançando em nossos paradigmas ou nos deforma e nos engessa, calando ou anulando nossa voz. Porém, em uma situação ou outra, somente nós, ali, nos limites desse espaço, é que podemos, através da reflexão e do trabalho coletivo, sustentar nossos olhares e perspectivas marcando nossas posições em prol de uma profissionalização viva.

É um compromisso político com a profissão na afirmação constante de se viver a cidadania com os valores éticos do estar em comunidade.

\section{Produções e áreas de atuação: a parceria possível}

Em nossa formação e atuação, enfrentamos situações muito adversas, na maioria das vezes. Portanto, estarmos numa perspectiva coletiva produtiva é o ideal, embora isso não seja Revista Interinstitucional Artes de Educar. Rio de Janeiro, V. 7, N. 1 - pág. 686-700 janeiroabril de 2021: "Pedagogias Vitais: Corpo, Desejo e Educação" DOI: 10.12957/riae.2021.53461 
fácil, pois as diferenças fazem de nós uma multiplicidade de professores.

Contudo, é muito importante que o docente tenha um par para trocar mais de perto. Isso fortalece a prática de ambos e mobiliza muitas considerações importantes. É claro que, para que essa sintonia seja produtiva, é importante que tenham mais semelhanças que diferenças a unir num trabalho uníssono.

Não existe a primeira nem a última palavra, e não há limites para o contexto dialógico (este se estende ao passado sem limites e ao futuro sem limites). Nem os sentidos do passado, isto é, nascidos no diálogo dos séculos passados, podem ser estáveis (concluídos, acabados de uma vez por todas): eles sempre irão mudar (renovando-se) no processo de desenvolvimento subsequente, futuro do diálogo. (BAKTHIN, 2003, p. 410)

Assim, as parcerias são importantes no trabalho na construção dos sentidos, identificação e legitimação ao que se faz e se produz. Como também aprendemos o que desejamos através do que não queremos ser. Observar a prática de outro docente, compartilhar ideias e trabalhar com as diferenças de cada um também contribui para sermos o que somos.

Trabalhar em parceria é um grande desafio, mas um aprendizado qualitativo muito significativo para quem se dispõe a fazer esse movimento de troca, de ir ao encontro do outro.

Assinar um trabalho, compartilhar ideias, referendar as concepções que o outro tem sobre ele mesmo e sobre o trabalho que executa é tentar a todo o momento chegar a um denominador comum que precisa se constituir de elementos básicos, mas importantes, como: confiança, ética, respeito, cuidado, competência profissional e pessoal e o próprio trabalho.

Trabalhar além das obrigações institucionais não é fácil porque a ordem natural da dinâmica da vida não permite, mas subvertemos cotidianamente esse movimento, quando constituímos isso tudo em teorias e práticas de sucesso, onde mais do que a nossa presença física, o imaterial intelectual da parceria caminha para além dos muros dos nossos espaços. $\mathrm{O}$ trabalho toma uma identidade que ecoa a voz de uma simbiose carregada da práxis pedagógica. Não é apenas o "um”, mas o "dois”, a parceria, a dupla que marca a importância do coletivo.

Cada coletivo tem a sua marca, a sua história e traz no seu bojo elementos que lhe são caros e próprios. Podemos dizer que a parceria, o trabalho construído, que a cada dia aprimoramos e estreitamos, nos permite sermos melhores profissionais, pesquisadoras, indo à busca de uma identidade sólida.

O que começou como um trabalho, onde deveríamos empregar esforços para que se afinasse, por si só se mostrou inteiro, perfeito e com uma única linguagem. Deu certo sem que precisássemos fazer algum movimento. 
Encontrar no outro essa ligação de trabalho que nos instiga a um desenvolvimento constante, a criar e a ser o diferencial no meio da multidão e não cairmos na mediocridade é um grande ganho, não somente profissional, mas pessoal.

Os caminhos que nos foram apresentados, inicialmente, se desenvolveram, avançaram e criaram laços e expressões que se traduziram em muitos projetos e trabalhos em comum, e a possibilidade de assinarmos as nossas produções intelectuais e reafirmamos a nossa posição como responsáveis pelo trabalho que executamos.

Um caminho, que na atualidade percorre mundos que outrora não imaginávamos, mas que confirma a fidelidade e lealdade não somente com a parceria, mas, principalmente, com o discurso ideológico que assumimos e representa a nossa identidade profissional-formadora.

Nossas contribuições foram nas reuniões de Centros de Estudos que se realizavam nas escolas por onde percorremos como regentes, discutindo, planejando ações, revendo posições. Depois, em outros espaços de formação, realizando formações com professores sobre processos de alfabetização, assim como, em políticas de formação para alfabetizadores como o PNAIC (Pacto Nacional da Alfabetização na Idade Certa).

De lá pra cá, temos produzido textos e artigos, participando de Simpósios, Congressos, entre outros, onde temos a oportunidade de compartilharmos experiências, ofertando e recebendo conhecimentos. E assim, vamos apurando nossos processos de autoria, autonomia e autoridade no fluxo dos sentidos de ser professor, um sentido nunca dado e acabado.

\section{Conclusão}

Temos a ideia de que a profissionalização docente não é algo dado, mas sim construído, e que, nessa construção, vai nos constituindo enquanto profissional, atravessando nossa identidade pessoal e docente por várias interferências. Essas interferências são constituídas através das práticas sociais, das formações pelas quais os docentes passam, tanto no início de carreira quanto ao longo dela e através também das disposições legais e curriculares no âmbito das políticas de educação.

Atuar na Rede Municipal de Ensino do Rio de Janeiro, vem nos permitindo contribuir e repensar a nossa prática e, ao mesmo tempo, consubstanciando nossas vozes, em prol de um trabalho de formação com nossos pares desde a escola e ampliando nossa atuação para outras esferas de formação docente, dentro e fora dessa Rede que nos retroalimenta. 
É uma trajetória abarcada de obstáculos do cotidiano os mais diferenciados entre si, mas que encontra uma intersecção positiva quando vemos o produto de nosso trabalho, a partir das reflexões e observações que vamos conseguindo fazer, de análises que vamos aprendendo a fazer da nossa práxis, cruzando percepções e valores dessa prática com o conjunto de coletivos de trocas com outros docentes e com os próprios discentes ao longo da profissão.

Esse caminho, na maioria das vezes, começa tímido, acanhado, mas vai se robustecendo diante das experiências vivenciadas, diante de referências e vai se transformando pela práxis. Na verdade, essa transformação é a linha mestra desse percurso, pois nunca somos os mesmos. É sempre um vir a ser! Não conseguimos delimitar um início ou término nesse processo, se é que há, mas, mais do que estabelecer um tempo cronológico, devemos pensar nas qualidades das relações que existem e são incorporadas. Nas várias interseções diárias que acontecem e nos fazem novos profissionais da educação.

A conscientização sobre os processos de autoria, autoridade e autonomia do trabalho docente é um movimento emancipatório que se desenvolve durante a profissionalização. Mas para que eles ganhem vigor em nossas práticas, a consciência do fazer pedagógico necessita ser estimulada, cuidada, provocada.

O educador é o agente ativo dessa construção que se inicia, por vezes, sem que a própria pessoa se perceba como elemento disparador desse processo, mas que qualitativamente, traz um suporte bem importante para o alcance do trabalho.

Um trabalho construído e constituído por diversas vozes, personas, ideias... que balizam e estruturam o profissional docente, formando-o, trazendo novas imagens e entendimentos sobre a profissão. Esses elementos, dentre outros, compõem-se em deslocamentos de vivências que vão contribuindo para uma tomada de consciência sobre o seu fazer.

Grande desafio é este, mas um desafio que se transforma em novas possibilidades de ampliação de conhecimentos e principalmente, de relações.

Pensar na tríade proposta por nós é empoderar o nosso trabalho como autoras, cientes da responsabilidade que temos como pesquisadoras, construtoras teóricas, educadoras que procuraram repensar, replanejar ao longo da trajetória profissional. Um amadurecimento dos nossos pontos de vista, da visão de mundo e daquilo que pretendemos como fim do nosso trabalho.

Uma trajetória cheia de contornos que traduzem o quanto carregamos e pudemos assinar confirmando a competência profissional que desejamos ser/fazer. E assim, sermos referenciais para os que nos rodeiam, mas muito mais para com aquilo que nos define profissionalmente: a nossa identidade. E isso só se torna materializado e possível a partir do momento que passamos Revista Interinstitucional Artes de Educar. Rio de Janeiro, V. 7, N. 1 - pág. 686-700 janeiroabril de 2021: "Pedagogias Vitais: Corpo, Desejo e Educação" DOI: 10.12957/riae.2021.53461 
a nos auto observar e ponderar nossas observações, representações, crenças, paradigmas e saberes no trato com nossos pares e através da realidade. Portanto, é um processo de reflexão contínua e coletiva que nos dá consistência sobre nossos processos de autoria, autoridade e autonomia, categorias fundamentais no constante vir a ser docente.

Acreditamos que nossa história em comum de trabalho, de parceria profissional, caminhou por esses três campos, já definidos ao longo deste artigo, tendo como mote a autoria, autoridade e autonomia. Constituíram-nos como formadoras e reforçaram a nossa atuação docente, onde uma pôde apoiar a outra, ponderando, reconfigurando e reavaliando a prática. Percebemos o quanto isso é necessário ao crescimento do profissional da educação.

Uma parceria que a cada dia se solidifica, amadurece e se confirma como vitoriosa nos espaços de atuação e onde podemos mostrar, onde muitas das vezes fomos buscar a oportunidade do desafio e não ficamos esperando ela acontecer. Então, isso é da ordem da curiosidade, da ousadia, do lançar-se.

A cada dia nos afirmamos como precursoras de nós mesmas, nos desafiando nessa empreitada em prol de uma educação qualitativa, significativa que se (re)faz nas idas e vindas de um processo histórico da qual cada uma de nós também faz parte, tendo o exercício da ética e da reflexão como amparos para os passos que vamos ensaiando, fazendo e concluindo em nossos espaços reais e virtuais.

É ir além das possibilidades que nos permitem e que o nosso cotidiano de trabalho nos impõe, enfrentando por meio de uma racionalidade as múltiplas interpretações que a vida profissional nos apresenta, frente a tantas e inúmeras contradições da contemporaneidade e das características do contexto nacional. Um trabalho de resistência e de luta em defesa da docência!

\section{REFERÊECIA}

BAKTHIN, Mikhail. Estética da Criação Verbal. Introdução à tradução do russo Paulo Bezerra: prefácio à edição francesa Tzvetan Todorov, $4^{\mathrm{a}}$ ed.: Martins Fontes, 2003 - (Coleção biblioteca universal).

FREIRE, Paulo. Pedagogia da Autonomia: saberes necessários à prática educativa. São Paulo: Paz e Terra. 1996. (Coleção Leitura).

. Pedagogia do Oprimido. 17 ed. Rio de janeiro, Paz e Terra, 1987.

Conscientização: teoria e prática da libertação: uma introdução ao pensamento de Paulo Freire. $3^{a}$ ed. - São Paulo, 1980.

Revista Interinstitucional Artes de Educar. Rio de Janeiro, V. 7, N. 1 - pág. 686-700 janeiro-

abril de 2021: "Pedagogias Vitais: Corpo, Desejo e Educação" DOI: 10.12957/riae.2021.53461 
FOUCAULT, Michel. A ética do cuidado de si como prática da liberdade. In: Ética, sexualidade e política, por Michel FOUCAULT. Rio de Janeiro: Forense Universitária, 2004a.

Disponível em http://coralx.ufsm.br/revce/revce/2004/02/a5.htm. Acesso em mar de 2019.

Disponível em https://meuartigo.brasilescola.uol.com.br/educacao/a-instituicao-escolar-nasociedade-contemporanea.htm. Acesso em jan de 2019.

\begin{abstract}
${ }^{i}$ Doutoranda em Educação pela UNILOGOS. Mestre pela UNICARIOCA em Novas Tecnologias Digitais na Educação Possui Especialização em Mídias Educativas, Docência do Ensino Superior e Neuropsicologia, Psicopedagogia, Gestão Escolar e Coordenação Pedagógica. Graduada em História pela Universidade Federal do Estado do Rio de Janeiro (2014), graduação em Teologia pela Pontifícia Universidade Católica do Rio de Janeiro (2009) e graduação em Pedagogia pela Universidade do Estado do Rio de Janeiro (2002). Professora de Monografia I - CEDERJ/UERJ/PEDAGOGIA. Orientadora de Monografia Cederj/Uerj/Pedagogia. Coordenadora Pedagógica da Rede Municipal de Ensino do Rio de Janeiro há 13 anos, com 25 de experiência na Educação Básica e com projetos premiados pela própria Rede de Ensino. Tem experiência na área de Educação, com ênfase em Tecnologia Educacional Digital, Alfabetização, Sala de Leitura, Políticas Públicas Educacionais e Formação de Professores. Participantes dos seguintes Grupos de Pesquisa: GEFEL e Pedagogia Histórico Crítica da UERJ. É membro do grupo 500womenscientists.org. Foi membro participante do EPELLE/LEDUC/UFRJ de 2017 até maio/2019. Colunista do Jornal MAIS MINAS e do Grupo Dogus de Comunicação. Colunista do Jornal TANGARÁ/ISERJ. Poetisa com publicação de 2 livros autorais e diversos trabalhos na área literária. Trabalhou por 3 anos como Orientadora de Estudos do PNAIC/MEC, sendo também professora e formadora na área da Informática Básica e Educativa. Idealizadora, fundadora e mediadora do Curso Laboratório de Aprendizagem Tecnológica pertencente ao Espaço Ação. Pesquisadora em Novas Tecnologias Digitais na Educação, Formação Docente, Alfabetização e Políticas Públicas Educacionais. Rio de Janeiro/RJ- Brasil. ORCID iD: http://orcid.org/0000-0002-5082-3537.

ii Mestranda em Educação pela Universidade Estadual do Rio de Janeiro. Possui especialização em Produção do Conhecimento na Escola Básica: Da Pré-Escola à $4^{\mathrm{a}}$ série pela Universidade Federal Fluminense e pela CEFETRJ em Relações Etnicorraciais e Educação. Especialista em Psicopedagogia pela PUC-Rio e UNINTER-PR. É graduada em PEDAGOGIA pelo Centro de Ciências Humanas e Sociais Instituto Isabel. Atualmente, trabalha na Coordenação de Integração e Gestão da Secretaria Municipal de Educação do Rio de Janeiro. Tem experiência na área de Educação e na formação de professores, com ênfase em alfabetização. Foi Orientadora de Estudos do PNAIC (Pacto Nacional de Alfabetização na Idade Certa) em 2013/2014. Membro do https://500womenscientists.org/. Participou do grupo de pesquisa EPELLE/ LEDUC da UFRJ de 2017 a 2019.Idealizadora, fundadora e mediadora do Curso Laboratório de Aprendizagem Tecnológica pertencente ao ESPAÇO AÇÃO de minha propriedade. Participante do Grupo de Pesquisa Pedagogia Histórico Crítica (PHC) da UERJ. Colunista do Jornal TANGARÁ/ISERJ - Instituto Superior de Educação do Rio de Janeiro. Rio de Janeiro/RJ- Brasil. ORCID iD: http://orcid.org/0000-0002-9386-6967.
\end{abstract}

